\title{
Care Coordination and Population Management Services Are More Prevalent in Large Practices and Patient-centered Medical Homes
}

\author{
Miranda Moore, PhD, Lars Peterson, MD, PhD, Megan Coffman, MA, and \\ Yalda Jabbarpour, MD
}

Despite efforts to better coordinate health care and improve population health, primary care practices may face difficulty dedicating an individual to provide these services. Using data from the American Board of Family Medicine, we found that the presence of care coordinators or population health managers was higher in larger practices and those with patient-centered medical home certification. ( $\mathrm{J}$ Am Board Fam Med 2016;29:652-653.)

Keywords: Certification, Delivery of Health Care, Family Practice, Health Services, Patient-centered Care

With the passage of the Medicare Access and CHIP Reauthorization Act in 2015, Congress intends to improve the quality of care through valuebased purchasing under the Merit-based Incentive Payment System program. Comprehensive Primary Care Plus is a Medicare-funded effort to radically expand practice transformation. For both of these efforts to succeed, primary care practices will need to coordinate care for their patients and provide population health management services. Having a staff member function as a care coordinator has been associated with improved quality through increased medication adherence and enhanced chronic disease care and preventive care. ${ }^{1}$ Similarly, many care coordinators provide popula-

This article was externally peer reviewed.

Submitted 1 June 2016; revised 6 September 2016; accepted 7 September 2016.

From the Department of Family and Preventative Medicine, Emory University, Atlanta, GA (MM); the Robert Graham Center, Washington, DC (MC, YJ); and the American Board of Family Medicine, Lexington, KY (LP).

Funding: none.

Conflict of interest: Dr. Peterson is an employee of the American Board of Family Medicine.

Corresponding author: Lars Peterson, $\mathrm{MD}, \mathrm{PhD}$, American Board of Family Medicine, 1648 McGrathiana Pkwy, Ste 550, Lexington, KY 40511 (E-mail: lpeterson@theabfm.org).

See Related Commentary on Page 649. tion health management services, which have been associated with reduced utilization and costs. ${ }^{2,3}$ Some primary care practices may face challenges in providing personnel dedicated to coordinating care for their patients, particularly small practices and those that have not undergone patient-centered medical home (PCMH) transformation.

We used data from family physicians recertifying with the American Board of Family Medicine in 2014 and 2015. A practice demographic questionnaire is a mandatory part of the application. In these years, one fourth of applicants were asked, using a round-robin method, whether their practice had access to someone who functions as a care coordinator or provides patient population management services. Respondents were also asked whether their practice was a $\mathrm{PCMH}$ and the number of providers in their practice. We compared the percentage of respondents reporting the presence of a care coordinator or population health manager by PCMH status and practice size.

Just over half $(53.1 \%)$ of the 4649 respondents reported having a care coordinator or population health manager. Respondents in solo and non$\mathrm{PCMH}$ practices reported the lowest presence of care coordinators, at $27.0 \%$ (158 of 586), whereas nearly $90 \%$ (354 of 395 ) of those in large PCMH practices ( $\geq 20$ providers) reported having a care coordinator (Figure 1).

If effectively designed and implemented, care coordination and population health management each 
Figure 1. Percentage of family physicians reporting having a care coordinator or population health manager at their primary practice, by practice size and patient-centered medical home (PCMH) status. Nearly one-third (31.2\%) reported working in a PCMH; $14.2 \%$ were in a solo practice, $35.8 \%$ in small practices, $31.4 \%$ in mediumsized practices, and 18.6\% in large practices. Source: American Board of Family Medicine 2014 to 2015 Maintenance of Certification Demographic Survey.

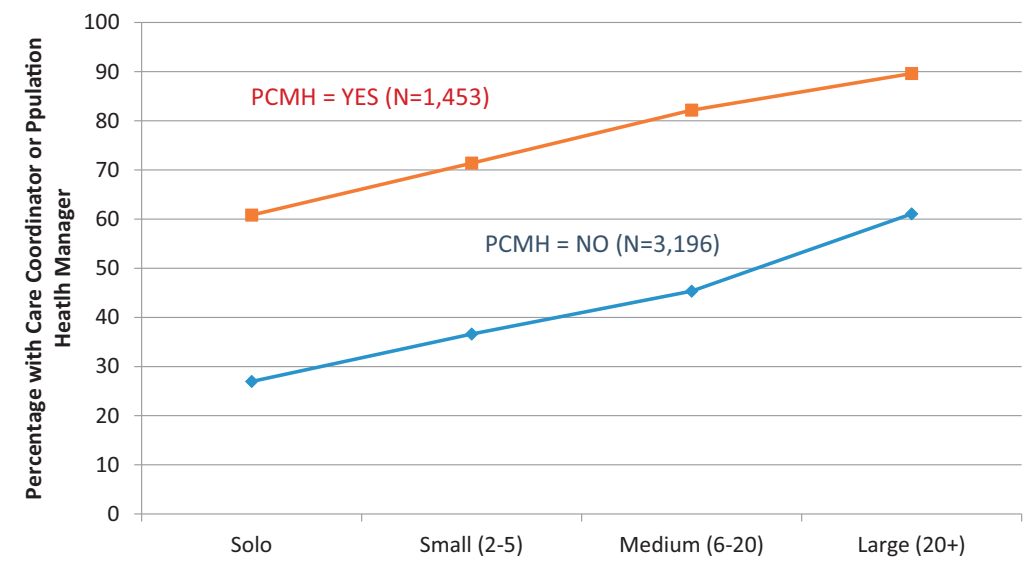

have the potential to improve patients' well-being and together are 1 of the 10 building blocks of highperforming primary care. ${ }^{3-5}$ Having a dedicated staff member provide such services may be ideal to ensure these functions are conducted, but such personnel seem to be disproportionately prevalent in large practices and PCMHs. Stakeholders should consider ways new programs such as the Merit-based Incentive Payment System and the Comprehensive Primary Care Initiative can be tailored to better meet the needs of small practices and those that have yet to transform to a PCMH to ensure they meet their intended goals of improving quality.

\section{References}

1. Mullins A, Mooney J, Fowler R. The benefits of using care coordinators in primary care: a case study. Fam Pract Manag 2013;20:18-21.
2. Nelson L. Lessons from Medicare's demonstration projects on disease management and care coordination. Congressional Budget Office issue brief 2012. Available from: www.cbo.gov/sites/default/files/112th-congress2011-2012/reports/01-18-12-MedicareDemoBrief.pdf. Accessed September 2, 2016.

3. Brown RS, Peikes D, Peterson G, Schore J, Razafindrakoto CM. Six features of Medicare coordinated care demonstration programs that cut hospital admissions of high-risk patients. Health Aff (Millwood) 2012;31:1156-66.

4. Bodenheimer T, Ghorob A, Willard-Grace R, Grumbach K. The 10 building blocks of high-performing primary care. Ann Fam Med 2014;12:16671.

5. Peikes D, Chen A, Schore J, Brown R. Effects of care coordination on hospitalization, quality of care, and health care expenditures among Medicare beneficiaries: 15 randomized trials. JAMA 2009; 301:603-18. 